\title{
How to Turn Strategies into Results-Based Actions
}

\author{
H. Butuner, Ph.D. \\ President of Industrial Management and Engineering Co., Istanbul \\ President of Institute of Industrial Engineers (IIE) Turkey Professional Chapter, Istanbul
}

\begin{abstract}
The purpose of this paper is to help businesses to answer the question of "how can we reach our target destination?" to be coherent with the whole of strategies. This requires using a practical and beneficial approach.

Accordingly, the business will describe the activities and projects required for the realization of this strategy in detail. This is the plan when actions are prepared to identify by whom, how and when the strategy created to achieve strategic objective and goals will be implemented within the business, the action plans created are communicated and implemented within the business. This also involves the preparation of budgets for utilization of resources required for realization of action plans.

After expressing each goal in activities, activities must be linked to the budget. Then measure the activity costs by laying down the resource and cost structure during the budget preparation. Annual implementation portions of strategies will be identified and reported. The linkage between strategies and budgets will assume clarity through these documents.

Thus, budgets will be able to support performance implementation. Effective implementation of monitoring and evaluation activities requires linking the goals established into measurable indicators before proceeding into implementation.
\end{abstract}

In short, this paper helps a business to find out its way by offering a new and a practical approach.

Keywords: strategy performance; strategic planning; strategy implementation; strategy control

\section{Implementation Plan*}

This is the plan when actions are prepared to identify by whom, how and when the strategy created to achieve strategic objective and goals will be implemented within the business, the action plans created are communicated and implemented within the business.

The roles, responsibilities and powers of units in charge of implementing the strategy, i.e. providing the service, will be defined clearly within the organization within this plan.

The business has to make a prioritization during the implementation plan. After describing the goals prioritized, assigned to responsible units, the activities and projects required to achieve these goals will be explained in here in order of priority.

This also involves the preparation of budgets for utilization of resources required for realization of action plans (it must be remembered that the strategy has to be discussed and improved continuously, and necessary arrangements must be made in the action plans and budgets accordingly.)

The current status and potential of resource/expenditure structure will be taken into consideration. During prioritization, the principles of sustainability, efficiency, productivity, level of impact and relevance will also be taken into consideration (Figure 1).

* Adapted from (Butuner, 2015) 


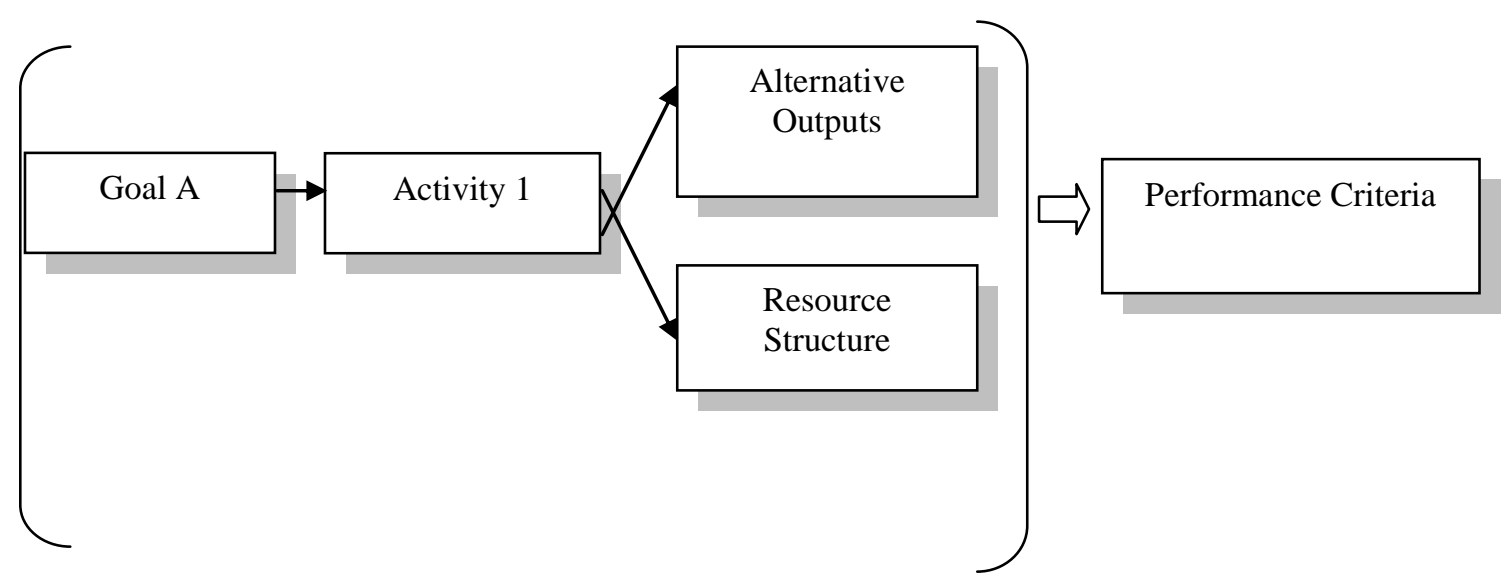

Figure 1. Goal, activity, output and performance relationship

Note, however, that businesses should shape their budget structures by taking as a basis their strategies.

After expressing each goal in activities, activities must be linked to the budget (Table 1).Then measure the activity costs by laying down the resource and cost structure during the budget preparation and prioritizing the expenditures.

Annual implementation portions of strategies will be identified and reported. The linkage between strategies and budgets will assume clarity through these documents. Thus, budgets will be able to support performance implementation.

Key questions required to be answered during the identification of activities:

- What is the role and importance of the activity in the process of achieving the goal?

- Have the way and techniques to be followed for the achievement of goals been defined?

- On which measurable criteria (forming the basis of performance criteria) are they based?

○ Timing

$\circ$ Quantity

○ Cost

$\circ$ Quality

- Which units are in charge of achieving the goals and performing the activities under the goals, and what are their responsibilities?

- Have alternative activities to achieve the same goal been identified and discussed?

Factors to be considered in identifying and implementing activities:

- Activities and projects interacting with each other must be properly placed and timing must be established accordingly.

- Each activity must be oriented towards a specific goal.

- They must not overlap with other projects and goals.

- The business most adopt an approach that considers not only the present time and current state, but also medium and long-term expectations and changes, when identifying and implementing the activities and projects. Note, however, that interruption or failure of short-term or annual implementation would negatively affect the implementation of strategy.

- While designing the implementation, the units to implement the projects and activities must be identified and the assigned authorities and responsibilities must be clear. 
- While implementing activities and projects, it is important to ensure cooperation and coordination between other businesses and related parties.

Table 1. Activity-Cost Worksheet

\section{Strategic Objective1}

Goal 1.1

\begin{tabular}{|l|l|l|l|l|}
\hline \multicolumn{1}{|c|}{ Activities } & Current Year (t) & $\begin{array}{c}\text { Budget Year } \\
(\mathbf{t}+\mathbf{1})\end{array}$ & $\begin{array}{c}\text { Following First } \\
\text { Year (t+2) }\end{array}$ & $\begin{array}{c}\text { Following Second } \\
\text { Year (t+3) }\end{array}$ \\
\hline Activity 1.1.1 & & & & \\
\hline Activity 1.1.2 & & & & \\
\hline Activity 1.1.3 & & & & \\
\hline Activity 1.1.4 & & & & \\
\hline$\cdots . .$. & & & & \\
\hline
\end{tabular}

Dissemination: A success beyond expectations can be achieved when business goals are reduced from the highest level of the organization to the lowest levels successfully and are disseminated to all related activities horizontally.

In the implementation plan, the strategies must be disseminated to all levels of the business and shared. A significant portion of strategic plan should be expanded by following a top-down approach hierarchically. The expansion of goals must cover all hierarchical levels of the business vertically and must be disseminated to all related areas and activities horizontally. During the top-down expansion of strategies, the results intended to be achieved in any level must constitute a goal for the immediate lower level.

The expansion of goals in any level must be intended to achieve the immediate higher goal. Department goals must be identified accordingly, and individual goals must be explained.

\section{Monitoring and Evaluation}

A strategy has a dynamic and continuous character (Porter, 2002). Any major change may require a series of changes in strategies. For instance, a major change in the economic circumstances of the country may pose a threat or offer an opportunity for the long-term goals of the business, eventually requiring the business to change its longterm goals and strategy.

In addition, plan realizations are reported annually during the implementation of the strategies. During the strategic planning process, feedback is provided using the information obtained as a result of monitoring and evaluation activities (Pearce \& Robinson, 2011). Review of strategies involves the comparison of the results targeted and attained. Plan realizations are reviewed in terms of timing and relevance for goals. As a result of this review and evaluation, the plan is confirmed and implementation continues if

- There is no fundamental change in the capacity of the business or in the external environment in which the business performs its operations

- Strategies, action plans and activities are implemented as planned

(C) 2018, IJSMS 
- Progress towards achievement of strategic objectives and goals is in line with expectations

On the other hand, if changes are observed in terms of the above considerations, unexpected or undesired results are coming about or existing strategic objectives and goals are not realistic, then the strategy is revised, reevaluated and is continues to be implemented with its updated version.

Effective implementation of monitoring and evaluation activities requires linking the goals established into measurable indicators before proceeding into implementation.

Monitoring and evaluation process ensures that activities are constantly improved. It is imperative that the activities covered by the strategies are subject to monitoring and evaluation. Otherwise, problems would be faced in enabling the accountability of related parties, in which case strategies would not go any further from just being a document. Basic questions in monitoring and evaluation:

- What did we do?

- How do we understand that we have achieved?

- How effective is implementation?

- What should be changed?

\subsection{Monitoring}

Monitoring activity consists of the regular reporting of progress towards achievement of objective and its submission to related parties and officials within the business for assessment.

Monitoring is a systematic activity assisting the management. Reports are used in monitoring; furthermore it focuses mainly on resources, activities and outputs.

Reporting is the primary instrument of monitoring activity. The contents of reports, the frequency by which they will be prepared, the units by which they will be prepared and the authorities to whom they will be presented have to be identified. A monitoring report must contain the following elements:

- Strategic objectives

- Goals

- Activities and projects

- Explanations and comments about realizations

- Information about the current status

Besides enabling the management to evaluate strategic objective and goals, monitoring report would help taking measures rapidly and effectively against unexpected cases.

In addition to areas where progress has been achieved, the issues on which progress could not be achieved must also be reported.

\subsection{Evaluation}

Evaluation is a comparative analysis of implementation results and pre-defined strategic objectives and goals. This process essentially involves performance measurement and evaluation.

Performance measurement and evaluation involve determining the extent by which the actualized results overlap with the pre-defined strategic objectives and goals. Performance measurement and evaluation:

- Ensure effectiveness of management

- Help measurable goals be achieved more easily

- Improve the quality of services

- Is helpful in development and review of budget

- Help answer the question why resources are spent for these activities

(C) 2018, IJSMS 
- Form the basis of accountability and performance audit

By following up the performance indicators, deviations from goals and the reasons of these deviations must be analyzed. Based on the results obtained, necessary revisions must be made to performance assessments, budget, activities and strategies.

Processes and sub-processes are meaningful if they are measurable and monitorable. For example, when the phrase high product quality is used alone, it is not possible to determine the actual level of product quality, the level of quality intended to be attained and whether progress or improvement has been achieved.

Therefore, critical performance indicators must be defined for each process and sub-process (Butuner, 2004). These indicators must not be hard and expensive to monitor in practice. Too many or hard-to-understand indicators must not be selected.

Performance indicators are instruments that ensure the measurement of the success of strategies and implementation results in particular. Performance indicators are categorized as input, output, productivity, result and quality indicators.*

Input

It is the financial and physical resources needed for the production of a good or service. Input indicators reflect the baseline status taken as a basis for measurement. For example,

- "Number of teachers needed."

Output

It is the quantity of goods or services produced. Although output indicators provide information about the quantity of goods and services produced, they are not descriptive alone as regards whether objectives and goals have been achieved or the quality of goods or services produced and efficiency of production process. For example,

- "Number of students taught."

Productivity

It represents the input or cost per output. It shows the linkage between inputs and outputs. For example,

- "Students success rate per teacher."

Result

Result indicators demonstrate how and to what extent the outputs obtained have been successful in achieving the strategic objective and goals. The level of success in achieving the targeted results is expressed by effectiveness. Result indicators are the most important performance indicators since they reveal whether the strategic objective and goals have been achieved. For example,

- "Improvement in students learning performance (based on worldwide accepted criteria.)"

\section{Quality}

The level attained in responding to the expectations of the beneficiaries of goods or services or measures like reliability, honesty, behavioral pattern, sensitivity and integrity. For example,

- "The rate of students rating the performance of teachers as minimum 9 on a scale of $10 . "$ 
In principle, at least one input, output, productivity, result and quality indicator must be defined for each goal. The quality of goals affects the quality of performance indicators as well. Another factor that must be considered in performance evaluation is the linkage of outputs to activities and the relevance of results for strategic objectives.

The creation and evaluation of performance indicators is only possible through obtainment of appropriate data and statistics. The availability of relevant, correct and consistent data is a sin qua non precondition for the creation of performance indicators and measurement and evaluation of performance. Questions like the types of data needed, the way how they will be obtained, how, by whom and by how often they will be provided and the constraints to be faced in this process need to be answered.

* Adapted from (Butuner, 2015)

\section{Conclusion}

Strategies are instruments for achievement of long-term goals. It is a course of action selected from a series of options in order to achieve a goal established against uncertainties.

The business will describe the activities and projects required for the realization of this strategy in detail. This is the plan when actions are prepared to identify by whom, how and when the strategy created to achieve strategic objective and goals will be implemented within the business.

After expressing each goal in activities, activities must be linked to the budget. Then measure the activity costs by laying down the resource and cost structure during the budget preparation. Budgets will be able to support performance implementation. Thus, effective implementation of monitoring and evaluation activities requires linking the goals established into measurable indicators before proceeding into implementation.

Accordingly, this paper is introduced to help businesses to answer the question of "how can we reach our target destination?" Thus, the intention here is to provide strategic planners an easily understandable and applicable new approach by assembling the disconnected and disorderly ideas and approaches.

\section{References}

[1] Bütüner, H. 2015. Systematic strategic planning: A comprehensive framework for implementation, control and evaluation. New York: Taylor \& Francis.

[2] Bütüner, H. 2004. Stratejik yönetim: Neden?Nasil?İstanbul: Rota Publications.

[3] Pearce, J. and R. Robinson. 2011. Strategic management: Formulation, implementation and control. Columbus: McGraw-Hill Higher Education.

[4] Porter, M. E. 2002. What is strategy? HBR on Point Enhanced Edition. Watertown: Harvard Business School Press. 